\title{
New Evidence on Efficiency in Southern European Banking
}

Simeon Papadopoulos, Stelios Karagiannis*

Abstract:

This paper explores the issue of efficiency in Southern European banking by applying the Fourier functional form and the stochastic cost frontier approach in calculating inefficiencies for a large sample of Southern European banks between 1997 and 2003. The findings suggest that the largest sized banks are generally the least efficient, while the smallest sized banks are the most efficient. The strongest economies of scale are displayed by Spanish banks, while the weakest economies of scale are reported by Greek banks. The findings suggest that medium-sized banks report the strongest economies of scale, and the largest and smallest banks weaker economies of scale (ranging between 3,5\% and 7\%). Therefore, the notion that economies of scale increase with bank size cannot be confirmed. The impact of technical change in reducing bank costs (generally about 3\% and 4\% per annum) appears to systematically increase with bank size. The largest banks reap greater benefits from technical change. Overall, the results indicate that the largest banks in the sample enjoy greater benefits from technical progress, although they do not have scale economy and efficiency advantages over smaller banks.

Keywords: Southern European banking; economies of scale; efficiency

JEL: G21, D21

DOI: $10.2478 / \mathrm{v} 10033-009-0001-8$

\section{Introduction}

The efficient-structure hypothesis suggests that banks that are able to operate more efficiently than their competitors incur lower costs and achieve higher profits and increased market shares that may result in increased concentration. Therefore, according to this hypothesis, efficiency positively influences both market shares and bank profits. This hypothesis is usually referred to as the X-efficiency hypothesis in order to distinguish it from the scale-efficiency hypothesis. The scale-efficiency hypothesis asserts that banks are equally X-efficient (the differences in the quality of management and in production technologies are negligible), and that some banks simply operate at a greater efficiency scale than others. Therefore, these banks enjoy higher profits and increased market shares.

The aim of this paper will be to calculate the cost characteristics of banking markets by applying the flexible Fourier functional form and stochastic cost

\footnotetext{
* Simeon Papadopoulos

Department of Accounting and Finance

University of Macedonia, Thessaloniki, Greece

e-mail: spapado@uom.gr

Stelios Karagiannis

Center of Programming and Economic Research

Athens, Greece
} 
frontier methodologies to estimate scale economies, Xinefficiencies and technical change for a large number of Greek, Italian, Spanish and Portuguese banks between 1997 and 2003. The results suggest that there exist both scale economies and $\mathrm{X}$-inefficiencies, with the latter being considerably greater (confirming the findings of previous studies), indicating that Southern European banks can significantly reduce their costs and increase their profits by eliminating $X$ inefficiencies. The impact of technical progress in reducing bank costs does not appear to differ according to bank size and ranges between 1,5 and $2 \%$, meaning that technical progress seemed to reduce bank costs by 1,5 to $2 \%$ per annum between 1997 and 2003. Section 2 presents a literature review of recent approaches to measuring X-efficiency in banking markets. Section 3 outlines this paper's methodology. Section 4 analyses the empirical results, and concluding comments are offered in Section 5 .

\section{The Measurement of X-Efficiency in Banking Markets}

Recent studies of the U.S banking market (Berger et al., 1993, Kaparakis et al., 1994, Mester 1996, Mitchell 1996) suggest significant $X$-inefficiencies exist across all bank sizes and that banks can considerably reduce their costs by eliminating them. They also present evidence pointing to the existence of both scale and scope economies of significantly smaller importance. Studies that have used the stochastic cost frontier approach include Berger and Humphrey (1991), Mester (1993, 1994), Cebenoyan et al. (1993), Elyasiani and Mehdian 1990a), Altunbas et al (1994a, 1994b, 1995), Drake and Weyman-Jones (1992) and Berger et al. (1993b), while studies that have used the DEA approach include Sherman and Gold (1985), Parkan (1987), Vassiloglou and Giolis (1990), Field (1990), Drake (1991), Elyasiani and Mehdian (1990b) and Berg et al. (1993).

Berger and Humphrey (1991) measured inefficiencies in U.S banking for 1984 using the thick frontier version of the stochastic cost frontier approach. Their results seem to suggest that there are significant inefficiencies in the banking system that are operational (stemming from overusing physical inputs), rather than scale or scope inefficiencies. The operational inefficiencies reached 20 to 25 percent, compared with 4.2 to 12.7 percent for scale inefficiencies. Based on these findings, Berger and Humphrey argued that banks would face substantial pressure to cut their costs following moves to deregulate the banking market. Alternatively, banks would have to merge with more efficient institutions or exit the market if they could not compete in an increasingly competitive environment.

Mester (1993) employed the stochastic cost frontier approach to investigate efficiency in American mutual and stock Savings and Loans (S\&Ls) institutions in 1991. The empirical findings suggested that, on average, stock S\&Ls are less efficient (based on different measures of inefficiency) than mutual S\&Ls. The study also found that capital to asset ratios are positively related with efficiency in both mutual and stock (shareholding) S\&Ls, and that the more S\&Ls rely on uninsured deposits the less efficient they are likely to be. In a similar study, Mester (1994) used the same methodology to study the efficiency of commercial U.S banks operating in the Third Federal Reserve District (parts of Pennsylvania and New Jersey, Delaware) for 1992. The author found significant X-inefficiencies ranging from 6 to 9 percent, although scale and scope inefficiencies were not observed. The $\mathrm{X}$-inefficiency result means that an average bank can reduce its production costs by between 6 to 9 percent if it uses its inputs as efficiently as possible (given its particular output level and output mix).

Cebenoyan et al. (1993) estimated inefficiency scores for 559 S\&Ls operating in the Atlanta Federal Home Loan Bank District in 1988, also using the stochastic cost frontier methodology. Their reported results seem to indicate that stock and mutual S\&Ls had very similar cost structures (contradicting Mester's findings) and therefore operating efficiency was not related to form of ownership (stock and mutual S\&LS). Moreover, the authors observed that the mean inefficiency score was 16 percent, which means that the average S\&L can produce its output by using only 84 percent of the amount of inputs actually used.

In their first study Altunbas et al. (1994a) evaluated inefficiencies for the German banking market, while in 
their later study (1994b) examined the Italian credit cooperative banking sector. The methodology used in both studies was the stochastic cost frontier approach. Altunbas et al. (1994a) distinguished between five categories of German banks:

private commercial banks, public savings banks, mutual cooperative banks, central organizations and mortgage banks. Their results indicated that the mean inefficiency score for all banks was 24 percent, suggesting that German banks could produce the same output with 76 percent of their inputs if they were operating efficiently. They also found that mortgage banks were less efficient than the other categories of banks, whereas different ownership characteristics did not seem to have a significant impact on the absolute level of bank inefficiencies in the German market

Altunbas et al. (1994b) analyzed the Italian credit cooperative banking sector between 1990 and 1992 . Their findings suggested that the mean inefficiency score for 1990 was 13.1 percent, but these scores appeared to be higher for 1991 and 1992. Moreover, the authors found that banks operating in the NorthEast Central region of Italy (Veneto and Emilia) were significantly less efficient than banks operating in the North-West and North-East border regions and in the South.

Altunbas et al. (2001) extended the established literature by modelling the cost characteristics of banking markets through the application of the flexible Fourier functional form and stochastic cost frontier methodologies (methodology adopted in this study) to estimate scale economies, $\mathrm{X}$-inefficiencies and technical change for a large sample of European banks between 1989 and 1997. The results reveal that scale economies are widespread for smallest banks (are found to range between $5 \%$ and $7 \%$ ), while $X$ inefficiency measures appear to be much larger, between $20 \%$ and $25 \%$. X-inefficiencies also appear to vary to a greater extent across different markets, bank sizes and over time. This suggests that banks of all sizes can obtain greater cost savings through reducing managerial and other inefficiencies. Their findings also indicated that technical progress has had a similar influence across European banking markets between
1989 and 1997, reducing total costs by around 3\% per annum.

Drake and Weyman-Jones (1992) used both the DEA and stochastic cost frontier approaches to compare the efficiency of the U.K. building societies. Their results of the DEA analysis showed that British building societies had a mean inefficiency score of 12.5 percent. Overall efficiency was partitioned into two components: technical efficiency and allocative efficiency. It was found that allocative efficiency accounted for most of the overall efficiency index. Drake and Weyman-Jones argued that their findings suggested that most of the inefficiency that was associated with the U.K building society sector was attributable to a less than optimal allocation of inputs rather than to the inefficient use of these inputs. Furthermore, the findings of the stochastic cost frontier analysis confirmed their DEA results and, moreover, showed that productive inefficiency scores were very low.

Finally, Berger et al. (1993b) used a stochastic cost frontier approach and found that larger banks were on average substantially more X-efficient than smaller banks and suggested that this finding may offset some of the diseconomies of scale that were found to characterise larger banks in many cost studies.

Rangan (1988) and Elyasiani and Mehdian (1990a) tried to break down banking inefficiencies into two distinct groups: pure technical inefficiencies and scale inefficiencies. Rangan (1988) analysed the cost structures of 215 U.S banks and found that the average measure of inefficiency (almost all of which is attributed to pure technical inefficiency) was 30 percent, which means that the banking output could be produced with only 70 percent of the inputs. Elyasiani and Mehdian (1990a) used a sample of 144 U.S banks and estimated that scale inefficiencies reached a very significant value of 38.9 percent, while pure technical inefficiencies were measured at only 11.7 percent, thus attributing vital importance to scale inefficiencies in contrast to Rangan's findings.

Two other studies undertaken by Field (1990) and Drake et al. (1991) applied the DEA methodology to the building societies sector in the U.K. Field (1990) examined 71 building societies in 1981 and concluded that 61 of them were operating inefficiently primarily 
due to scale inefficiencies, confirming Elyasiani and Mehdian's (1990a) results. Moreover, Field showed that the overall technical efficiency of banks was negatively related to bank size, in contrast to the findings of most U.S studies that seem to indicate that technical efficiency is actually positively associated with bank size. Drake et al. (1991) found that 63 percent of the building societies included in his sample were inefficient (compared with 86 percent in Field's study) and overall efficiency appeared to be positively related to bank size (contradicting Field's result).

Overall, U.S studies that used the stochastic cost frontier methodology to estimate inefficiency, have generally found average banking inefficiency to be around 20-25 percent. On the other hand, U.S studies that used the DEA methodology have reported findings ranging from around 10 percent to more than 50 percent. These findings are in line with the European stochastic cost frontier studies that generally tend to report low inefficiency scores (between 10 and 20 percent).

\section{The Methodology}

The stochastic cost frontier approach is used in this paper to calculate inefficiency scores for all the banks included in the sample. The stochastic cost frontier approach assumes that a firm's observed cost deviates from the cost frontier because of a random error and possible inefficiency. The cost function that will be estimated adopts the flexible Fourier functional form (following Altunbas et al., 2001), including a standard translog and all first-, second- and third-order trigonometric terms, as well as a two-component error structure, and is estimated using a maximum likelihood procedure. The translog cost function is specified as follows:

$$
\begin{array}{r}
+\sum_{i=1}^{3} \sum_{m=1}^{3} \rho_{i m} \ln Q_{i} \ln P_{m}+\sum_{i=1}^{3} K_{i l} \ln P_{i} \ln E+\sum_{i=1}^{3} \sigma_{i l} \ln Q_{j} \ln E+\sum_{i=1}^{3} X_{i} T \ln Q_{i} \\
\sum_{l=1}^{3} \omega_{l} T \ln P_{l}+\sum_{i=1}^{4}\left[a_{i} \cos \left(z_{i}\right)+b_{i} \sin \left(z_{i}\right)\right] \\
\sum_{i=1}^{4} \sum_{j=1}^{4}\left[a_{i j} \cos \left(z_{i}+z_{j}\right)+b_{i j} \sin \left(z_{i}+z_{j}\right)\right]+\varepsilon
\end{array}
$$

where

In TC = natural logarithm of total costs (financial costs and operating costs) In $Q_{i}=$ natural logarithm of bank outputs In $P_{l}=$ natural logarithm of input prices (interest rates, wage rates etc) In $E=$ natural logarithm of equity capital $T=$ time trend

$Z i=$ the adjusted values of the $\log$ output $(\operatorname{In} Q, \ln E)$ such that they span the interval $(0,2)$ $\alpha, \beta, \lambda, \delta, \gamma, \tau, \phi, \rho, \kappa, \sigma, \chi, \omega, a$ and $b$ are coefficients to be estimated

Since the duality theorem requires that the cost function must be linearly homogenous in input prices, the following restrictions are imposed on the parameters of equation (1):

$$
\begin{gathered}
\sum_{l=1}^{3} \beta_{l}=1 ; \sum_{l=1}^{3} \gamma_{l m}=0 ; \sum_{l=1}^{3} \omega_{l}=0 ; \sum_{m=1}^{3} \rho_{i m}=0, \\
\delta_{\mathrm{ij}}=\delta_{\mathrm{ji}} \text { and } \gamma_{\mathrm{lm}}=\gamma_{\mathrm{ml}}
\end{gathered}
$$

Following Mester (1996) and Altunbas et al. (1994), we estimate economies of scale by calculating the elasticity of cost with respect to output, holding the product mix and non-output variables constant. A measure of overall economies of scale is given by the following cost elasticity, obtained by differentiating equation (1) with respect to output: 


$$
\begin{gathered}
S E=\sum_{i=1}^{3} \theta \ln T C / \theta \ln Q_{i}=\sum_{i=1}^{3} \alpha_{i}+\sum_{i=1}^{3} \sum_{j=1}^{3} \delta_{i j} \ln Q_{j}+ \\
\sum_{i=1}^{3} \sum_{m=1}^{3} \rho_{\text {im }} \ln P_{m}+\sum_{i=1}^{3} \varphi_{i} T+ \\
+\mu_{i} \sum_{i=1}^{3}\left[-a_{i} \sin \left(Z_{i}\right)+b_{i} \cos \left(Z_{i}\right)\right]+ \\
+2 \mu_{i} \sum_{i=1}^{3} \sum_{j=1}^{3}\left[-a_{i j} \sin \left(Z_{i}+Z_{i j}\right)+b_{i j} \cos \left(Z_{i}+Z_{j}\right)\right]
\end{gathered}
$$

if $\mathrm{SE}<1$ there are increasing returns to scale, which implies economies of scale

if $\mathrm{SE}=1$ there are constant returns to scale and

if $\mathrm{SE}>1$ there are have decreasing returns to scale, which implies diseconomies of scale

Scale economy estimates can also be derived for various bank sizes by calculating equation (3) using different mean values for output and input prices for each bank group. Firm-specific scale economy estimates are obtained by using firm-specific output and input prices. Technical progress is measured, as in McKillop et al. (1996) and Lang and Welzel (1996), by the partial derivative of the estimated cost function with respect to the time trend $T^{1}$ and is given by

$$
\frac{\theta \ln T C}{\theta T}=\tau_{1}+\tau_{11} T+\sum_{l=1}^{3} \omega_{l} \ln P_{1}+\sum_{i=1}^{3} K_{i} \ln q_{i}
$$

\section{Empirical Results}

This study uses bank balance sheets and income statement data from a number of Greek, Italian, Spanish and Portuguese banks between 1997 and 2003 obtained from the London based International Bank Credit Analysis Ltd's Bankscope database.

\footnotetext{
${ }^{1}$ This T time trend variable is used as a proxy for disembodied technical change and is inferred from changes in a firm's cost function over time. It captures all the effects of technological factors (learning by doing, other organizational changes etc.). Technical progress means that a firm can produce a given output $Q$ using lower levels of total inputs and hence producing at lower cost.
}

The figures reported in Tables 1-5 indicate that among the four national banking markets under investigation, Portuguese banks were the least efficient (mean 0.2317) and Spanish banks were the most efficient (mean 0.2118) with Italian and Greek banks in the middle (mean 0.2145 and 0.2256 respectively). The mean inefficiency score of 23.17 percent reported for Portuguese banks means that they could produce the same output with only 76.83 percent of the inputs if they were operating efficiently. By the same token, Spanish banks could produce the same output with 78.82 percent of the inputs. The inefficiency scores for each national market are very similar, however, and they are in line with other studies' findings (see Evanoff and Israilevich 1991, Altunbas et al. 2001).

The analysis of bank inefficiency scores in each country separately reveals which size of bank (size is measured by total assets) operates more efficiently than others. In Greece, the largest banks (those with total assets exceeding $€ 20$ billion) were the least efficient throughout the period 1997-2003, while the medium sized banks (total assets $€ 2-€ 20$ billion) were the most efficient (although the smallest sized institutions were not far behind). These figures also suggest that the maximum inefficiency score recorded by a Greek bank reached a substantial 0.3762 , while the minimum was 0.1494 .

With regard to Italian banks, while the largest banks seem to be the most inefficient (as in the Greek sample), the smallest banks are the most efficient throughout the period in consideration. The maximum inefficiency score recorded by an Italian bank was 0.3874 and the minimum was 0.1385 .

The inefficiency scores reported for Spanish and Portuguese banks are compatible to those of the Greek and Italian banks. The most important result that seems to apply in all national banking samples is that the largest sized banks are generally the least efficient banks and the smallest sized institutions appear to be the most efficient banks throughout the period 19972003. Therefore, inefficiency seems to increase with bank size, although only marginally. Another significant finding is that efficiency appears to improve with time, with all bank sizes reporting better efficiency 
scores for the years 2002-3 than 1997-8. This result applies to all four national banking markets.

The scale economy estimates shown in Tables 6-10 indicate that banks in all four markets are characterised by economies of scale. The strongest economies of scale are displayed by Spanish banks (inefficiency scores indicate that they are on average the most efficient banks as well). The economy of scale estimate of 0.9315 means that Spanish banks can double their output by increasing total costs by only 93.15 percent. The weakest economy of scale estimate is reported by Greek banks (0.9624), with Italian and Portuguese banks in between.

With regard to Greek banks, all bank sizes are found to enjoy economies of scale as well, with the medium sized banks (total assets $2 €-20 €$ billion) reporting the highest scale estimates, whereas the smallest banks seem to be associated with weaker economy of scale estimates. Hence, economy of scale figures appear to improve as bank size increases, but only up to a point. The largest banks are not found to enjoy the strongest economies of scale. These findings are generally confirmed in the Italian, Spanish and Portuguese samples, with the best economy of scale figures associated with medium sized banks. The largest banks are found to display diseconomies of scale for 2002-3. Therefore, this paper cannot confirm the assumption that the size of a bank is directly proportional to its economy of scale. Seeking a stronger economy of scale hence is not an incentive for increasing bank size. Moreover, in all four national samples, economies of scale seem to increase with time, with better figures reported for the later years than the earlier years in the period studied. These findings are generally in line with results reported in previous studies (Vennet 1993, Altunbas et al. 2001 and others).

Estimates of technical change are shown in Tables 1115. The results suggest that technical change plays an important role in all four banking markets by reducing the annual costs of production by about 3-4\% per annum. Greek and Portuguese banks are found to be more positively influenced by the effects of technical change (3,9\% and 4,2\% respectively), with Spanish and Italian banks following at $3,2 \%$ and $3,4 \%$. The impact of technical change in reducing bank costs appears to systematically increase with bank size. The findings suggest that the largest banks in our sample are reaping the greatest benefits from technical change $(4,3 \%)$ and that medium sized banks enjoy the lowest benefits $(2,8 \%)$. This finding is confirmed in all four national banking markets under examination. ${ }^{2}$ These results are in line with earlier findings (Altunbas et al. 2001).

\section{Conclusion}

This paper uses the flexible Fourier functional form and the stochastic cost frontier methodologies to estimate $\mathrm{X}$-inefficiencies, scale economies and technical change for a sample of Greek, Italian, Spanish and Portuguese banks between 1997 and 2003. The results indicate that inefficiencies range between $20 \%$ and $25 \%$ in all four national samples. Portuguese banks were the least efficient (mean 0.2317) and Spanish banks were the most efficient (mean 0.2118) with Italian and Greek banks in the middle (mean 0.2145 and 0.2256 respectively). The findings suggest that the largest sized banks are generally the least efficient banks and the smallest sized institutions appear to be the most efficient banks throughout the period 19972003. Therefore, inefficiency seems to increase with bank size, although only marginally. Another significant finding is that efficiency appears to improve with time, with all bank sizes reporting better efficiency scores for the years 2002-3 than 1997-8. This result applies to all four national banking markets.

The reported figures for scale economy estimates indicate that banks in all four markets are characterised by economies of scale. The strongest economies of scale are displayed by Spanish banks (inefficiency scores indicate that they are on average the most efficient banks as well), while the weakest economies of scale are reported by Greek banks, with Italian and Portuguese banks in between. Generally, scale economies are found to range between 3,5\% and $7 \%$. Typically, medium sized banks report the strongest economies of scale, while the largest and smallest

\footnotetext{
2 These estimates should be treated with caution given the problems associated with this method of measuring technical change, as Hunter and Timme (1991) have pointed out.
} 
banks report weaker economies of scale. Therefore, the notion that economies of scale increase with bank size cannot be confirmed. However, economies of scale seem to increase with time, with better figures reported for the later years than the earlier years in the period studied. Therefore, as bank size increases above medium sized banks, inefficiencies increase and economies of scale weaken, providing evidence that the largest bank size is not optimal.

The impact of technical change in reducing bank costs appears to systematically increase with bank size. The findings suggest that the largest banks in the sample reap greater benefits from technical change $(4,3 \%)$. Greek and Portuguese banks are more positively influenced from the effects of technical change, with Spanish and Italian banks only marginally behind. Technical progress reduces banking costs between $3 \%$ and $4 \%$ per year. The findings of this study are generally in line with earlier results applying similar methodologies in E.U banking markets. Researchers in the future may examine whether these relationships hold for private, mutual and public banks. $[$.

\section{References}

D. Aigner, C. Lovell and P. Schmidt. (1977), Formulation and estimation of stochastic frontier production models. Journal of Econometrics 21-37.

L. Allen and A. Rai. (1993), Global financial intermediation: universal versus specialised banking, Paper presented at the 20th annual meeting of the European Finance Association, Copenhagen Business School, Published in section II - D of the Proceedings, 1-33.

Y. Altunbas, P. Molyneux and N. B. Murphy. (1994), Privatisation, efficiency and public ownership in Turkey: an analysis of the banking industry - 1991 to 1993, IEF Research Papers (University of Wales, Bangor).

Y. Altunbas and P. Molyneux. (1995), Cost economies in E.U banking systems, IEF Research Papers (University of Wales, Bangor).

Y. Altunbas, E. M. H. Liu, P. Molyneux and R. Seth (2000), Efficiency and risk in Japanese banking, Journal of Banking and Finance (24), 1605-1628.

Y. Altunbas, E. P. M. Gardener, P. Molyneux and B. Moore (2001), Efficiency in European banking, European Economic Review 45, 19311955.

Y. Altunbas, L. Evans and P. Molyneux (2001), Bank ownership and efficiency, Journal of Money, Credit and Banking, 926-954.
Y. Altunbas, S. Carbo, E. P. M. Gardener and P. Molyneux (2007), Examining the relationship between capital, risk and efficiency in European banking, European Financial Management

S. A. Berg, F. R. Forsund, L. Hjalmarsson and M. Suominen. (1993), Banking efficiency in the Nordic countries, Journal of Banking and Finance, 371-88.

A. N. Berger. (1995), The profit-structure relationship in banking. Tests of market power and efficient structure hypotheses, Journal of Money, Credit and Banking, 404-31.

A. N. Berger and D. B. Humphrey. (1991), The dominance of inefficiencies over scale and product mix economies in banking. Journal of Monetary Economics 28 (1), 117-148.

A. N. Berger, G. A. Hanweck and D. B. Humphrey. (1987), "Competitive viability in banking: scale, scope and product mix economies". Journal of Monetary Economics, 501-20.

A. N. Berger, W. C. Hunter and S. G. Timme. (1993), The efficiency of financial institutions: a review and preview of research past, present and future, Journal of Banking and Finance, 221-49.

A. S. Cebenoyan, E. S. Cooperman, C. A. Register and S. C. Hudgins. (1993), The relative efficiency of stock vs mutual S\&Ls: a stochastic cost frontier approach, Journal of Financial Services Research, 151-70.

L. Drake. (1992), Economies of scale and scope in U.K building societies: an application of the translog multiproduct cost function, Loughborough University of Technology Economic Research Paper No. 92/10.

L. Drake and T. G. Weyman-Jones (1992), Productive and allocative inefficiencies in U.K Building societies: a comparison of nonparametric and stochastic frontier techniques, Loughborough University of Technology Economic Research Paper No. 92/2.

E. Elysiani and S. Mehdian. (1990), Efficiency in the commercial banking industry: a production frontier approach, Applied Economics, 539-51.

E. Elysiani and S. Mehdian. (1990), A non-parametric approach to measurement of efficiency and technological change: the case of large U.S banks. Journal of Financial Services Research, 157-68.

D. Evanoff and D. Fortier. (1988), Re-evaluation of the s-c-p paradigm in banking, Journal of Financial Services Research, 277-294.

D. Evanoff and P. Israilevich. (1991), Productive efficiency in banking, Economic Perspectives, Federal Reserve Bank of 'Chicago, 1132.

K. Field. (1990), Production efficiency of British building societies, Applied Economics, 415-25

W. H. Greene. (1993), Econometric Analysis, New York: Macmillan.

W. C. Hunter and S. G. Timme (1991), Technological change in large U.S commercial banks, Journal of Business 64, 339-362.

J. Jondrow, C. A. Lovell, I. S. Materov and P. Schmidt. (1982), On estimation of technical inefficiency in the stochastic frontier production function model, Journal of Econometrics, 233-38. 
E. I. Kaparakis, S. M. Miller and A. G. Noulas (1994), Short-run cost inefficiencies of commercial banks, Journal of Money, Credit and Banking 26, 875-893.

L. J. Mester. (1987), A multi-product cost study of savings and loans, Journal of Finance, 423-445.

L. J. Mester. (1993), Efficiency in the savings and loan industry. Journal of Banking and Finance, p.p 267-87.

L. J. Mester. (1996), A study of bank efficiency taking into account risk preferences, Journal of Banking and Finance 20, 1025-1045.

K. Mitchell and N. M. Onvural (1996), Economies of scale and scope at large commercial banks: Evidence from the Fourier flexible functional form, Journal of Money, Credit and Banking 28, 178-199.

D. G. McKillop, J. C. Glass and Y. Morikawa (1996), The composite cost function and efficiency in giant Japanese banks, Journal of Banking and Finance 20, 1651-1671

G. Lang and P. Welzel (1996), Efficiency and technical progress in banking: empirical results for a panel of German cooperative banks, Journal of Banking and Finance 20, 1003-1023.

A. G. Noulas, S. C. Ray and S. M. Miller. (1990), Returns to scale and input substitution for large U.S banks, Journal of Money, Credit and Banking.

S. Papadopoulos (2004), Market structure, performance and efficiency in European banking, International Journal of Commerce and Management 14, 79-98.

C. Parkan. (1987), Measuring the efficiency of service operations: an application to bank branches, Engineering Costs and Production Economics, p.p 237-42.

I. Sherman and F. Gold. (1985), Bank branch operating efficiency: evaluation with data envelopment analysis, Journal of Banking and Finance, p.p 297-316.

M. Smirlock. (1985), Evidence on the (non) relationship between concentration and profitability in banking, Journal of Money, Credit and Banking.

M. Smirlock, T. Gilligan and W. Marshall. (1984), Tobin's q and the structure-performance relationship, American Economic Review.

M. Vassiloglou and D. Giolis. (1990), A study of the relative efficiency of bank branches: an application of Data Envelopment Analysis, Journal of Operational Research Society, 591-97.

R. V. Vennet (1993), Cost characteristics of credit institutions in the E.C. Paper presented at the $10^{\text {th }}$ annual meeting of the European Finance Association, Copenhagen Business School, published in section II-D of the proceedings, 1-38.

A. M. Yuengert. (1993), The measurement of efficiency in life insurance: estimates of a mixed normal-gamma error model, Journal of Banking and Finance, 483-96.

\section{Annex}

\begin{tabular}{|c|c|c|c|c|c|}
\hline Assets size $(\mathrm{m} €)$ & Mean & Median & StDev. & Min. & Max \\
\hline $0-500$ & 0.2159 & 0.204 & 0.0522 & 0.1243 & 0.3869 \\
\hline $500-2000$ & 0.2148 & 0.2216 & 0.0453 & 0.1562 & 0.3782 \\
\hline $2000-10000$ & 0.2123 & 0.2154 & 0.0551 & 0.1628 & 0.3712 \\
\hline $10000-20000$ & 0.2196 & 0.2019 & 0.0246 & 0.1672 & 0.3465 \\
\hline$>20000$ & 0.2285 & 0.2452 & 0.0435 & 0.1862 & 0.3476 \\
\hline Greece(all banks) & 0.2256 & 0.2114 & 0.0634 & 0.1494 & 0.3762 \\
\hline Italy (all banks) & 0.2145 & 0.2482 & 0.0724 & 0.1385 & 0.3874 \\
\hline Spain (all banks) & 0.2118 & 0.2576 & 0.0254 & 0.1314 & 0.3756 \\
\hline Portugal(all banks) & 0.2317 & 0.2018 & 0.0355 & 0,1518 & 0.3917 \\
\hline
\end{tabular}

Table 1: Descriptive statistics of inefficiency scores (1997-2003).

\begin{tabular}{|c|c|c|c|c|c|c|c|}
\hline Ass size $(\mathbf{m} \boldsymbol{\epsilon})$ & $\mathbf{1 9 9 7}$ & $\mathbf{1 9 9 8}$ & $\mathbf{1 9 9 9}$ & $\mathbf{2 0 0 0}$ & $\mathbf{2 0 0 1}$ & $\mathbf{2 0 0 2}$ & $\mathbf{2 0 0 3}$ \\
\hline $\mathbf{0 - 5 0 0}$ & 0.2316 & 0.2348 & 0.2417 & 0.2335 & 0.2253 & 0.2216 & 0.2143 \\
\hline $\mathbf{5 0 0 - 2 0 0 0}$ & 0.2362 & 0.2227 & 0.2246 & 0.2252 & 0.2143 & 0.2192 & 0.2186 \\
\hline $\mathbf{2 0 0 0 - 1 0 0 0 0}$ & 0.2264 & 0.2295 & 0.2342 & 0.2209 & 0.2258 & 0.2164 & 0.2108 \\
\hline $\mathbf{1 0 0 0 0 - 2 0 0 0 0}$ & 0.2212 & 0.2241 & 0.2264 & 0.2231 & 0.2269 & 0.2284 & 0.2345 \\
\hline$>\mathbf{2 0 0 0 0}$ & 0.2415 & 0.2452 & 0.2359 & 0.2335 & 0.2263 & 0.2408 & 0.2316 \\
\hline
\end{tabular}

Table 2: Inefficiency scores for Greek banks 